\title{
Mediation of transfer motivation on the relationship between trainee characteristics and transfer of training: evidence from educational sector in Nigeria
}

\author{
Wasilu Suleimana, Mudiyanselage Saman Dassanayake ${ }^{b}$ \\ and Abang Ekhsan Abang Othman ${ }^{c}$
}

aDepartment of Business Administration, Bauchi State University-Gadau, Bauchi, Nigeria; ${ }^{b}$ Graduate School of Business Administration, Meiji University, Tokyo, Japan; 'Faculty of Cognitive Sciences and Human Development, Universiti Malaysia Sarawak, Kuching, Malaysia

\begin{abstract}
This paper is ambitious of investigating the mediating role of transfer motivation on trainee characteristics in transferring training on the population of Nigerian teachers. An aggregate of 1,000 copies of the questionnaire was distributed to the respondents in an Education Board in Nigeria. Totally, 605 copies of the questionnaire were finally retained for analysis. Smart-PLS's measurement model, structural model and Sobel test were the techniques employed to assess and evaluate the statistical significance of relevant path coefficients. The findings showed that the extent to which employees are engrossed in organizational commitment and fully involved in their jobs would drive them to be desirous in making persistent and intense efforts towards utilizing skills and knowledge learned in the work settings. Also, the findings of this study highlighted that transfer motivation is a fundamental element in the transfer of training processes.
\end{abstract}

\section{ARTICLE HISTORY}

Received 12 April 2017

Accepted 15 August 2018

\section{KEYWORDS}

Organizational commitment; job involvement; transfer motivation; transfer of training; Nigeria

\section{Introduction}

The field of human resource development is built on three core areas, i.e. training and development, organizational development and change, and career development. Training has been identified as one of the key methods of maintaining organizational competitiveness in constantly changing environments and as a backbone for any meaningful and reasonable development. This is due to the fact that organizations need employees with higher productivity who can invest their best knowledge and skills in accomplishing the desired goals and objectives of the organization (Gunu et al. 2013).

In today's competitive world, training and development have become integral parts of most global organizations and are contributing immensely to the success and effectiveness of these organizations. Training and retraining of workers is frequently used as a means to address underperformance and increase performance. Chowdhury (2007) has pointed out that the complexity of modern jobs requires workers to be better trained than in the past. Meanwhile, organizations invest a considerable amount of 